\title{
Importance of the Noradrenaline-Dopamine Coupling in the Locomotor Activating Effects of D-Amphetamine
}

\author{
Laurent Darracq, Gérard Blanc, Jacques Glowinski, and Jean-Pol Tassin \\ Institut National de la Santé et de la Recherche Médicale U114, Collège de France, 75231 Paris Cedex 05, France
}

The locomotor hyperactivity induced by systemic or local (nucleus accumbens) D-amphetamine injections can be blocked by systemic or local (prefrontal cortex) injections of prazosin, an $\alpha 1$-adrenergic antagonist (Blanc et al., 1994). Microdialysis studies performed on freely moving animals indicated that prazosin $(0.5 \mathrm{mg} / \mathrm{kg}$, i.p.) does not modify the increase in the extracellular dopamine (DA) levels in the nucleus accumbens that are induced by D-amphetamine $(2.0 \mathrm{mg} / \mathrm{kg}$, i.p.), but it inhibits the D-amphetamine-induced locomotor hyperactivity $(-63 \%, p<0.0001)$. No behavioral activation occurred after the bilateral local perfusion of $3 \mu \mathrm{M}$ D-amphetamine in the nucleus accumbens, although it led to a fivefold increase in extracellular DA levels. This increase in extracellular DA levels was not affected by prazosin $(0.5 \mathrm{mg} / \mathrm{kg}$, i.p.). When an intraperitoneal injection of D-amphetamine $(0.5 \mathrm{mg} / \mathrm{kg})$ was superimposed to the continuous local perfusion of $3 \mu \mathrm{M}$ D-amphetamine, it induced a $64 \%$ increase in the extracellular
DA levels in the nucleus accumbens, and this response was associated with simultaneous behavioral activation. Both the increases in extracellular DA levels and in locomotor activity were completely blocked by a pretreatment with prazosin, injected either systemically $(0.5 \mathrm{mg} / \mathrm{kg}$, i.p.) or locally and bilaterally into the prefrontal cortex (500 pmol/side). Complementary experiments indicated that the focal application of $\mathrm{D}$-amphetamine requires at least a 4.8-fold higher increase in DA output compared with systemic D-amphetamine for the behavioral effects to be elicited. Altogether, these results suggest that locomotor activating effects of D-amphetamine are caused by the stimulation of cortical $\alpha 1$-adrenergic receptors by noradrenaline, which increases the release of a functional part of subcortical DA.

Key words: NA-DA coupling; D-amphetamine; prazosin; Iocomotor activity; prefrontal cortex; nucleus accumbens; microdialysis; $\alpha 1$-adrenergic receptors
When used in behaviorally effective doses, one of the primary actions of D-amphetamine is to increase the release and to block the reuptake of dopamine (DA) in the brain (Besson et al., 1971; Von Voigtlander and Moore, 1973). Considerable evidence suggests that the D-amphetamine-induced psychomotor activation mainly results from an increased DA transmission in the nucleus accumbens. For example, the locomotor hyperactivity induced by the intraperitoneal injection of D-amphetamine is antagonized by the application of neuroleptics into the nucleus accumbens (Pijnenburg et al., 1975) and is disrupted after bilateral 6-hydroxydopamine lesions of the dopaminergic neurons projecting to this structure (Kelly et al., 1975).

Because of its higher behavioral activating potency, D-amphetamine has been more widely used in experimental studies than its isomer, L-amphetamine. Accordingly, D-amphetamine is threefold to sevenfold more potent than its isomer in inhibiting DA uptake into dopaminergic neurons. However, both isomers are equally more active as inhibitors of catecholamine accumulation into noradrenergic than in dopaminergic neurons (Heikkila et al., 1975; Andersen, 1989). Similarly, D-amphetamine is 6- to 10 -fold more active than L-amphetamine in inhibiting the firing rate of mesencephalic dopaminergic neurons located in the sub-

\footnotetext{
Received Nov. 10, 1997; revised Jan. 12, 1998; accepted Jan. 15, 1998.

This study was supported by Ministère de l'éducation nationale de l'enseignement supérieur et de la recherche Grant $97 \mathrm{H} 0003$ and Philip Morris Europe. We thank Fabienne Blanchet for her advice in statistical analysis and Marie-José Melle for technical support.

Correspondence should be addressed to Dr. Laurent Darracq, Institut National de la Santé et de la Recherche Médicale U114, Collège de France, 11 Place Marcelin Berthelot, 75231 Paris Cedex 05, France.

Copyright (C) 1998 Society for Neuroscience $\quad 0270-6474 / 98 / 182729-11 \$ 05.00 / 0$
}

stantia nigra (SN) or the ventral tegmental area (VTA) (Bunney et al., 1975; Wang, 1981), and both isomers are equally more active in decreasing the firing rates of noradrenergic cells of the locus ceruleus than those of mesencephalic dopaminergic neurons (Bunney et al., 1975; Bunney and Aghajanian, 1976, 1978; Wang, 1981; Akaoka et al., 1991). In this context, it is interesting to note that the development of $\mathrm{D}$-amphetamine-induced locomotor hyperactivity occurs in the range of the lower doses, i.e., those that inhibit noradrenergic cells but do not decrease dopaminergic cell firing (Bunney et al., 1975; Lyon and Robbins, 1975; Wang, 1981; Porrino et al., 1984). Moreover, in clinical studies, both D- and L-amphetamine are approximately equipotent in inducing psychosis and in exacerbating schizophrenia symptoms (Angrist et al., 1971, 1974; Janowski and Davis, 1976). It is therefore not entirely clear whether the primary behavioral effects obtained with systemic injections of D-amphetamine are caused by an increased transmission of DA or noradrenaline (NA).

The role of noradrenergic neurons in the behavioral effects of D-amphetamine may indeed be more important than generally accepted. For example, both the circling behavior and the increase in startle arousal induced by D-amphetamine are antagonized by pretreatment with bis-(l-methyl-4-homopiperazinylthiocarbonyl)-disulfide, an inhibitor of DA- $\beta$-hydroxylase (Kokkinidis and Anisman, 1978, 1979). More recently, prazosin, an $\alpha 1$-adrenergic antagonist, has been shown to inhibit the locomotor hyperactivity induced by systemic D-amphetamine injections (Dickinson et al., 1988; Blanc et al., 1994). This effect is specific because the locomotor hyperactivity induced by scopolamine, an antimuscarinic agent, is not affected by prazosin (Blanc et al., 1994). Moreover, prazosin, injected bilaterally into the 
prefrontal cortex, was found to completely hamper the locomotor hyperactivity induced by the bilateral injection of D-amphetamine into the nucleus accumbens (Blanc et al., 1994). This suggests that cortical NA systems play a permissive role in the behavioral activation resulting from the increased DA transmission in the nucleus accumbens.

In this article, we have performed microdialysis studies on freely moving animals to understand how cortical NA systems interfere with the locomotor activity induced by the facilitation of DA transmission in the nucleus accumbens. First, D-amphetamine was injected systemically, locally in the nucleus accumbens, or both locally and systemically, and its effects on extracellular DA levels in the nucleus accumbens and on locomotor activity were analyzed. These effects were then compared with those obtained when prazosin was injected either systemically or locally into the prefrontal cortex before D-amphetamine. Experiments confirm that prazosin acts distally to the nucleus accumbens and indicate that locomotor hyperactivity induced by $\mathrm{D}$-amphetamine is more related to the pattern of DA release controlled by the noradrenergic neurons innervating the prefrontal cortex than to the absolute extracellular levels of DA in the nucleus accumbens.

\section{MATERIALS AND METHODS}

Subjects and surgery. Male Sprague Dawley rats (IFFA Credo, Lyon, France), weighing 350-400 gm at the time of surgery, were used as subjects. The rats were housed individually in plastic cages with food and water ad libitum. The colony room was maintained under constant temperature and humidity on a $12 \mathrm{hr}$ light/dark cycle (7:00 A.M. on, 7:00 P.M. off). One week or more before testing, the animals were anesthetized with $150 \mathrm{mg} / \mathrm{kg}$ ketamine (Imalgene; IFFA Mérieux, Lyon, France) and placed in a stereotaxic frame (Kopf Instruments). The skull was exposed, a burr hole was drilled over the nucleus accumbens, and the dura was incised. A permanent guide cannula with its obturator was stereotaxically implanted and secured on the skull by means of three screws and dental cement. The coordinates of the nucleus accumbens for the guide cannula tip were anteroposterior (AP), +1.5; mediolateral $(\mathrm{ML}), \pm 1$; and dorsoventral (DV), $-6 \mathrm{~mm}$ relative to bregma. Another group of animals was also implanted with bilateral injection cannulas and their obturators (22 and 30 gauge stainless steel tubing) in the prefrontal cortex (AP, +4 ; ML, \pm 0.7 ; and $\mathrm{DV},-4 \mathrm{~mm}$ relative to bregma). When animals were implanted with cannulas into the prefrontal cortex, it was verified $2-5 \mathrm{~d}$ before surgery that they were reactive to an intraperitoneal injection of $0.5 \mathrm{mg} / \mathrm{kg}$ D-amphetamine. After surgery, animals were placed into individual cages especially designed for microdialysis collection on freely moving rats and were allowed to recover for at least 1 week. At the end of the experiment, all animals were perfused transcardially with saline and $10 \%$ formalin solution under deep anesthesia. Histological verification of cannula tip placements was subsequently made on 40 $\mu \mathrm{m}$ cresyl violet-stained coronal sections.

Microdialysis procedure. The day of the experiment, the guide cannula obturator was replaced by a microdialysis probe (CMA Microdialysis $\mathrm{AB}$, Stockholm, Sweden) (membranes, $0.5 \times 2 \mathrm{~mm}$ ) designed in such a way that the entire length of the semipermeable membrane (cutoff, 20,000 Da) extended below the guide cannula tip after insertion. The location of the probe within the nucleus accumbens was confirmed histologically at the end of the experiments. Artificial CSF (in mM: 145 $\mathrm{Na}^{+}, 2.7 \mathrm{~K}^{+}, 1.2 \mathrm{Ca}^{2+}, 1 \mathrm{Mg}^{2+}, 150 \mathrm{Cl}^{-}$, and $2 \mathrm{Na}_{2} \mathrm{HPO}_{4}, \mathrm{pH} 7.4$ ) was perfused with a CMA/100 microinjection pump through the probe at a rate of $2 \mu \mathrm{l} / \mathrm{min}$ via capillary tubing connected to a fluid swivel. The tubing and swivel were supported by a counterweight assembly, thereby allowing the rat unrestricted movement. In preliminary experiments, it was verified that adequate equilibration of the extracellular DA levels collected after the perfusion of the artificial CSF was obtained in $<2 \mathrm{hr}$, and that basal extracellular DA levels were sensitive to the perfusion through the probe of tetrodotoxin (TTX) $(1 \mu \mathrm{M})$. Two hours after the insertion of the probe, perfusate samples were collected in $300 \mu \mathrm{l}$ vials placed in a refrigerated, computer-controlled fraction collector (CMA/ 170). The samples, collected every $5 \mathrm{~min}$ or every $1 \mathrm{~min}$ when D-amphetamine was perfused through the probe, were then rapidly frozen at $-80^{\circ} \mathrm{C}$.
Biochemistry. HPLC was performed with a reverse-phase column $(80 \times 4.6 \mathrm{~mm}, 3 \mu \mathrm{m}$ particle size; HR-80; ESA Inc., Chelmsford, MA). Mobile phase (in mM: $\mathrm{Na}_{2} \mathrm{HPO}_{4} 75$, EDTA 20, octane sulfonic acid 2.75, and triethylamine 0.7 , acetonitrile $6 \%$, and methanol $6 \%, \mathrm{pH} 5.2$ ) was delivered at $0.7 \mathrm{ml} / \mathrm{min}$ by an ESA-580 pump. Electrochemical detection was performed with an ESA coulometric detector (Coulochem II 5100A, with a 5014A analytical cell; Eurosep). The conditioning electrode was set at $-0.175 \mathrm{mV}$, and the detecting electrode was set at $+0.175 \mathrm{mV}$, allowing a good signal-to-noise ratio of the oxidization current of DA. External standards were regularly used to determine the stability of the sensitivity (0.1-0.2 pg of DA).

Dialysate samples $(2$ or $10 \mu \mathrm{l})$ were completed to $27 \mu \mathrm{l}$ with the mobile phase and placed in a refrigerated automatic injector (Triathlon; Spark Holland, Emmen, The Netherlands). Eighteen microliters of the sample were injected every $30 \mathrm{~min}$ through a rheodyne valve in the mobile phase circuit. The remaining $9 \mu \mathrm{l}$ were kept for an eventual subsequent analysis.

The mean basal values of nucleus accumbens extracellular DA levels were $0.44 \pm 0.03 \mathrm{pg} / \mathrm{min}$, taking into account the $4-6 \%$ recovery of the dialysis membrane and corresponding to a concentration of $16 \mathrm{nM}$ DA in the interstitial tissue of the nucleus accumbens.

Analysis of D-amphetamine diffusion in the nucleus accumbens. Two dialysis probes were placed $1 \mathrm{~mm}$ apart in the same nucleus accumbens, one medial to the other at its periphery (AP, $+1.5 ; 1.5$ and $0.5 \mathrm{~mm}$ lateral to the bregma, respectively). The medial probe (laterality, $1.5 \mathrm{~mm}$ ) was perfused with $500 \mu \mathrm{M}$ D-amphetamine, whereas the other one received only artificial CSF. Extracellular DA levels were simultaneously measured in both probes.

Behavioral scoring and pharmacological protocol. During the experiment, animals were monitored with a video camera. Quarter turns $\left(90^{\circ}\right.$ turns) in the dialysis chamber were counted as index of motor activity while dialysate samples were collected. In a first series of experiments, saline or prazosin $(0.5 \mathrm{mg} / \mathrm{kg}$, i.p.) was injected $30 \mathrm{~min}$ before the systemic injection of D-amphetamine ( $2 \mathrm{mg} / \mathrm{kg}$, i.p.). Extracellular DA levels in the nucleus accumbens were then estimated for $2 \mathrm{hr}$. In a second series of experiments, $3 \mu \mathrm{M} \mathrm{D}$-amphetamine was perfused through the dialysis probe. At least $30 \mathrm{~min}$ after establishment of stable extracellular DA levels induced by the perfusion of D-amphetamine, an intraperitoneal injection of either saline $(1 \mathrm{ml})$ or prazosin $(0.5 \mathrm{mg} / \mathrm{kg})$ was made. Thirty minutes later, all animals received an intraperitoneal injection of D-amphetamine $(0.5 \mathrm{mg} / \mathrm{kg})$, and extracellular DA levels were estimated for a further $80 \mathrm{~min}$. Rats that did not present a significant increase in extracellular DA levels in the nucleus accumbens after the local perfusion of $3 \mu \mathrm{M}$ D-amphetamine were not kept for further analysis. In a third series of experiments, bilateral infusions of 100,500 , or $1000 \mu \mathrm{M}$ D-amphetamine were performed for 20,30 , or $40 \mathrm{~min}$, respectively. Finally, in a fourth series of experiments, intracortical saline $(0.5 \mu \mathrm{l} / \mathrm{side})$ or prazosin $(500 \mathrm{pmol} / \mathrm{side}$ in $0.5 \mu \mathrm{l})$ injections were made, and this was followed $30 \mathrm{~min}$ later by an intraperitoneal injection of D-amphetamine $(0.5 \mathrm{mg} / \mathrm{kg})$.

Drugs. The drugs tested were either D-amphetamine dissolved in saline or artificial CSF and prazosin dissolved in water. D-Amphetamine sulfate (Sigma, St Louis, MO) was injected intraperitoneally (doses are expressed as sulfate) or perfused into the nucleus accumbens by reverse dialysis. Prazosin hydrochloride (Sigma) was injected either intraperitoneally or locally into the prefrontal cortex by simultaneous bilateral intracranial microinjection in unrestrained animals $(0.5 \mu \mathrm{l} /$ side over 45 sec with 30 gauge stainless steel injector cannulas connected via polyethylene tubing to $1 \mu$ l Hamilton syringes).

Statistics. All data are presented as mean \pm SEM. Statistical significance was assessed by two-way ANOVA. Individual values between amphetamine- and prazosin- plus amphetamine-treated rats were compared with a Mann-Whitney $U$ test and considered significant at $p<0.05$. Data from microdialysis are expressed as a percentage of the respective mean basal values to equate for between-subject differences. Activity scores were not converted to percentages, because untreated animals were almost inactive after being habituated to the chambers overnight.

\section{RESULTS \\ Lack of effect of systemic prazosin on increases of extracellular DA levels in the nucleus accumbens induced by an intraperitoneal injection of D-amphetamine}

As expected, the intraperitoneal injection of D-amphetamine (2 $\mathrm{mg} / \mathrm{kg}$ ) induced an increase of extracellular DA levels in the 


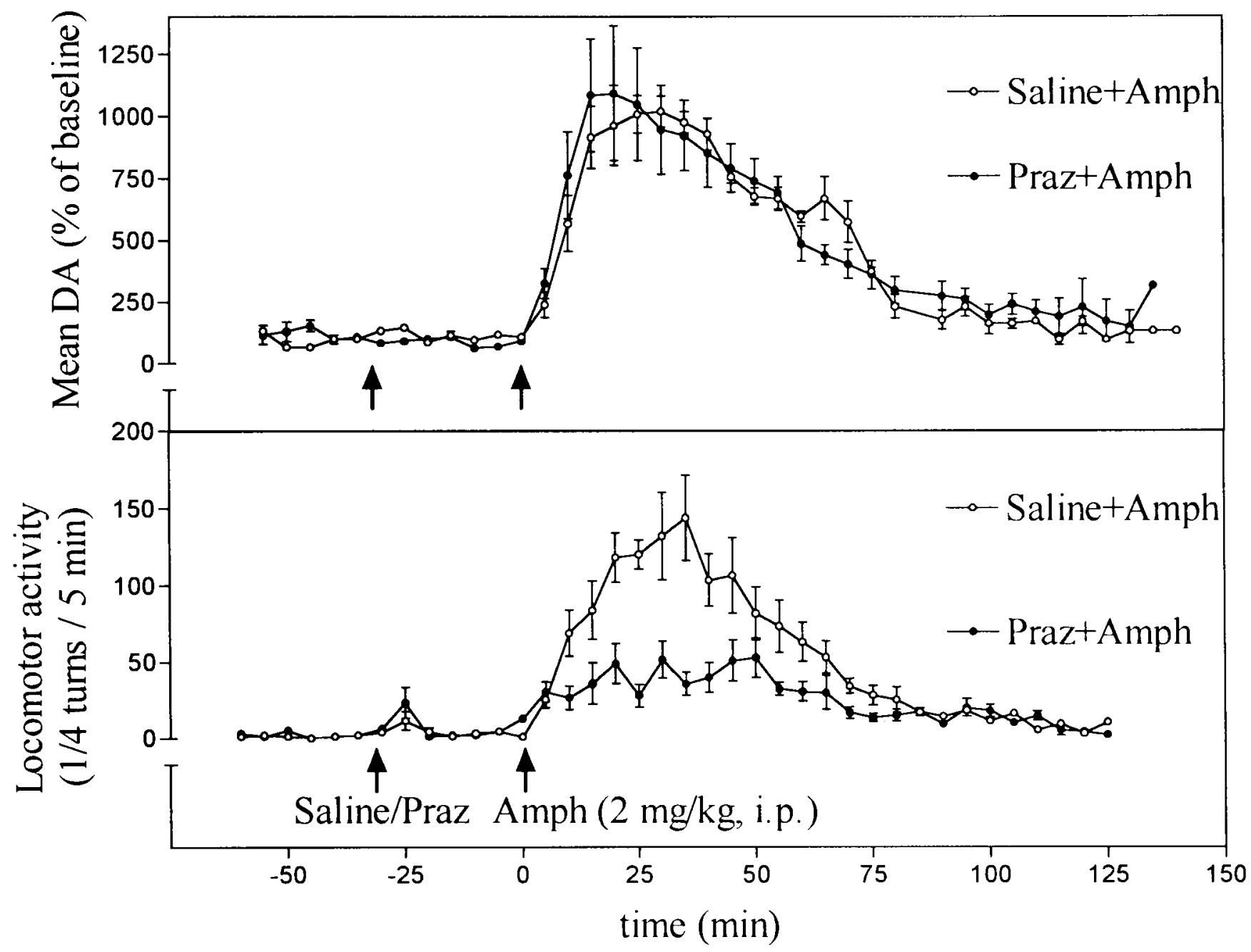

Figure 1. Dissociation between the effects of prazosin $(0.5 \mathrm{mg} / \mathrm{kg}$, i.p.) on increases of extracellular DA levels in the nucleus accumbens and on locomotor hyperactivity induced by a systemic injection of D-amphetamine $(2.0 \mathrm{mg} / \mathrm{kg}$, i.p. $)$. Thirty minutes after the injection of prazosin $(0.5 \mathrm{mg} / \mathrm{kg}$, i.p., $n=3)$ or saline $(n=4)$, D-amphetamine was injected intraperitoneally $(2 \mathrm{mg} / \mathrm{kg})$. Arrows indicate the time of saline-prazosin and D-amphetamine injections. Extracellular DA levels are expressed as the mean \pm SEM in percent of baseline defined as the mean value of six consecutive 5 min samples collected immediately before D-amphetamine intraperitoneal injections. Differences between saline plus amphetamine and prazosin plus amphetamine are not significant. Behavioral data are given in absolute values (mean \pm SEM). D-Amphetamine-induced hyperactivity is inhibited by prazosin injection $(-63 \% ; p<0.001)$.

nucleus accumbens $(+914 \%)$ and an important locomotor hyperactivity (Fig. 1). When prazosin (0.5 mg/kg, i.p.) was injected 30 min before D-amphetamine, locomotor hyperactivity was inhibited by $63 \%(p<0.0001)$, but the increase of extracellular DA levels in the nucleus accumbens stayed constant (+937\%) (Fig. 1). Basal levels of DA were identical, with or without prazosin pretreatment $(0.35 \pm 0.04$ and $0.32 \pm 0.05 \mathrm{pg} / \mathrm{min})$. Similarly, when a lower dose of D-amphetamine $(0.5 \mathrm{mg} / \mathrm{kg}$, i.p. $)$ was injected, prazosin $(0.5 \mathrm{mg} / \mathrm{kg}$, i.p. $)$ completely inhibited the D-amphetamine-induced locomotor hyperactivity (see Fig. 3) but had no effect on the increase of extracellular DA levels in the nucleus accumbens $(+350 \%$ of the basal values; data not shown). Histological examination of the brains after the experiments indicated that the probes were located in the shell or at the boundaries of the shell and the core parts of the nucleus accumbens (Zahm and Brog, 1992; Pierce and Kalivas, 1995).

These results may suggest that the effects of prazosin on D-amphetamine-induced locomotor hyperactivity are not related to changes in extracellular DA levels in the shell of the nucleus accumbens. However, because we had previously shown (Blanc et al., 1994) that the locomotor hyperactivity induced by a local injection of D-amphetamine in the nucleus accumbens could also be blocked by a prazosin pretreatment, a second series of experiments was performed in which D-amphetamine was administered locally by reverse dialysis.

\section{Lack of effect of an intraperitoneal injection of prazosin on the increased levels of DA induced in the nucleus accumbens by local perfusion of D-amphetamine}

A continuous perfusion of $3 \mu \mathrm{M} \mathrm{D}$-amphetamine in the probe located in the nucleus accumbens was chosen to obtain an approximately fivefold mean increase in DA levels (Fig. 2). This increase in DA levels is in the range of the changes observed after behaviorally active systemic injections of D-amphetamine (0.5 $\mathrm{mg} / \mathrm{kg}$, i.p.), in agreement with data obtained by others (Kuczenski and Segal, 1992; Cadoni et al., 1995; Pierce and Kalivas, 1995).

The mean increase in extracellular DA levels obtained after the 


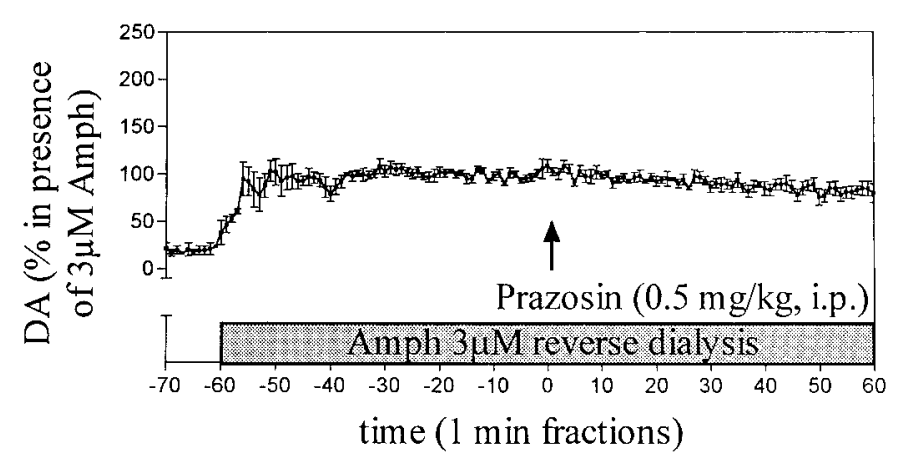

Figure 2. Lack of effect of intraperitoneal injection of prazosin $(0.5$ $\mathrm{mg} / \mathrm{kg}$ ) on the increase of extracellular DA levels induced by local perfusion of D-amphetamine. D-Amphetamine $(3 \mu \mathrm{M})$ was continuously perfused through the microdialysis probe. Prazosin $(0.5 \mathrm{mg} / \mathrm{kg}$, i.p. $)$ was injected at the time shown by the arrow. Data corresponding to the mean \pm SEM of results obtained in five animals are expressed as percent of baseline defined as the mean value of 30 consecutive samples collected immediately before prazosin administration.

local perfusion of $3 \mu \mathrm{M}$ D-amphetamine in the nucleus accumbens was $+360 \%(n=5 ; p<0.001)$ (Fig. 2). Once attained, this level of DA $(1.59 \pm 0.05 \mathrm{pg} / \mathrm{min})$ stayed almost constant as long as the perfusion was pursued for at least $90 \mathrm{~min}$ (Fig. 2). The limit of detection of DA (0.1-0.2 pg) was almost 10-fold lower than the extracellular DA levels attained with the D-amphetamine perfusion, and samples were collected every minute. Basal DA values $(0.34 \pm 0.02 \mathrm{pg} / \mathrm{min})$ were verified by pooling five consecutive samples. The increase in extracellular DA levels was never associated with behavioral change, even when D-amphetamine was perfused bilaterally into the nucleus accumbens, as shown on the fractions -60 to 0 in Figure 3. In this condition, the systemic injection of prazosin $(0.5 \mathrm{mg} / \mathrm{kg}$, i.p. $)$ did not modify the levels of DA (Fig. 3), indicating that, at this dose, prazosin does not interfere with the local action of D-amphetamine on DA levels.

\section{Effects of systemic injections of a low dose of D-amphetamine and prazosin on animals previously perfused locally in the nucleus accumbens with D-amphetamine}

As mentioned above, the perfusion of $3 \mu \mathrm{M}$ D-amphetamine in the nucleus accumbens induced an approximately fivefold increase in extracellular DA levels, but this response was not associated with a change in locomotor activity (Fig. 3). When D-amphetamine was injected intraperitoneally $(0.5 \mathrm{mg} / \mathrm{kg})$ in animals continuously perfused locally with $3 \mu \mathrm{M}$ D-amphetamine, it significantly increased extracellular DA levels in the nucleus accumbens ( $+64 \% ; p<0.001 ; n=6)$ and elicited locomotor hyperactivity, both responses lasting $\sim 60 \mathrm{~min}$ (Fig. 3). The injection of prazosin $(0.5 \mathrm{mg} / \mathrm{kg}$, i.p. $30 \mathrm{~min}$ before the systemic injection of D-amphetamine, suppressed, in all animals tested, both the changes in extracellular DA levels and the increased locomotor activity ( $n=5$; Fig. 3). Extracellular DA levels were significantly lower when prazosin, instead of saline, was injected $30 \mathrm{~min}$ before systemic D-amphetamine $\left(-41 \% ; F_{(1,490)}=1683\right.$; $p<0.0001)$.

\section{Analysis of the individual variations of DA levels induced by systemic injection of a low dose of D-amphetamine on animals previously perfused with D-amphetamine in the nucleus accumbens}

Data corresponding to the mean values of the modifications of extracellular DA levels in the nucleus accumbens induced by systemic D-amphetamine after D-amphetamine local perfusion appeared homogeneous (Fig. 3). However, observations of the individual changes indicated the presence of abrupt and shortlasting variations (Fig. $4 A$ ). The SD of consecutive samples taken every 5 min was therefore calculated for each animal (Fig. $4 C$ ) and compared with those obtained in basal conditions or when prazosin was injected $30 \mathrm{~min}$ before D-amphetamine (Fig. 4D). Figure $4 E$ shows that significantly larger SD values were observed $\sim 10$ and $40 \mathrm{~min}$ after the D-amphetamine injection $(+235 \% ; p<$ 0.05 ; and $+150 \% ; p<0.05$ at 10 and $40 \mathrm{~min}$, respectively) when compared with results obtained with animals pretreated with prazosin. These effects are not related to higher mean extracellular DA values obtained in the absence of prazosin, because identical results were obtained when the ratio of SD to mean DA values was plotted instead of SD alone (data not shown).

\section{Determination of the minimum D-amphetamine concentration eliciting locomotor hyperactivity when perfused bilaterally in the nucleus accumbens and its relation to the evoked changes in extracellular DA levels}

Different concentrations $(3, \quad 100,500$, and $1000 \mu \mathrm{M})$ of D-amphetamine were perfused through two microdialysis probes, each located in one nucleus accumbens to determine the minimum concentration of D-amphetamine required in this experimental condition for the development of locomotor hyperactivity. No locomotor activation could be observed up to $500 \mu \mathrm{M}$ D-amphetamine $(n=3$ for $500 \mu \mathrm{M})$, although extracellular DA levels reached $12,500 \%$ of their basal values (Fig. 5). When used at $1000 \mu \mathrm{M}$, D-amphetamine increased locomotor activity, and this response lasted up to $20 \mathrm{~min}$ after the interruption of the perfusion. With this latter concentration of D-amphetamine, extracellular levels of DA attained 25,000\% of the basal values (Fig. 5).

Increases of extracellular DA levels induced by local perfusion of D-amphetamine were then compared with those inducing locomotor hyperactivity after an intraperitoneal injection of 0.5 $\mathrm{mg} / \mathrm{kg}$ D-amphetamine. This comparison is shown in Figure 5, in which data from Figure 3 have been reported. Mean local increases of extracellular DA levels induced by the local perfusion of $1000 \mu \mathrm{M}$ D-amphetamine were found to be 48 -fold higher than those observed after the systemic injection of D-amphetamine, both treatments inducing, however, similar amplitude of locomotor hyperactivity.

A lack of diffusion of the perfused D-amphetamine throughout the nucleus accumbens could explain why it was necessary to induce a massive local increase in extracellular DA levels to evoke locomotor hyperactivity. Therefore, two microdialysis probes placed $1 \mathrm{~mm}$ apart were implanted, one in the middle of the nucleus accumbens, the other one at its periphery (Fig. 6). A $500 \mu \mathrm{M}$ concentration of D-amphetamine was perfused in the central probe, whereas the other one was perfused with the artificial fluid. Determinations in three different experiments of DA levels in superfusates collected from the two probes indicated that between 10 and $20 \%$ of DA measured in the central probe can be collected in the peripheral one (Fig. 6). This result indicates that the mean increases of extracellular DA levels in the entire nucleus accumbens that are necessary to elicit locomotor hyperactivity are at least 4.8-fold more important when $\mathrm{D}$-amphetamine is perfused locally than when it is injected systemically. 


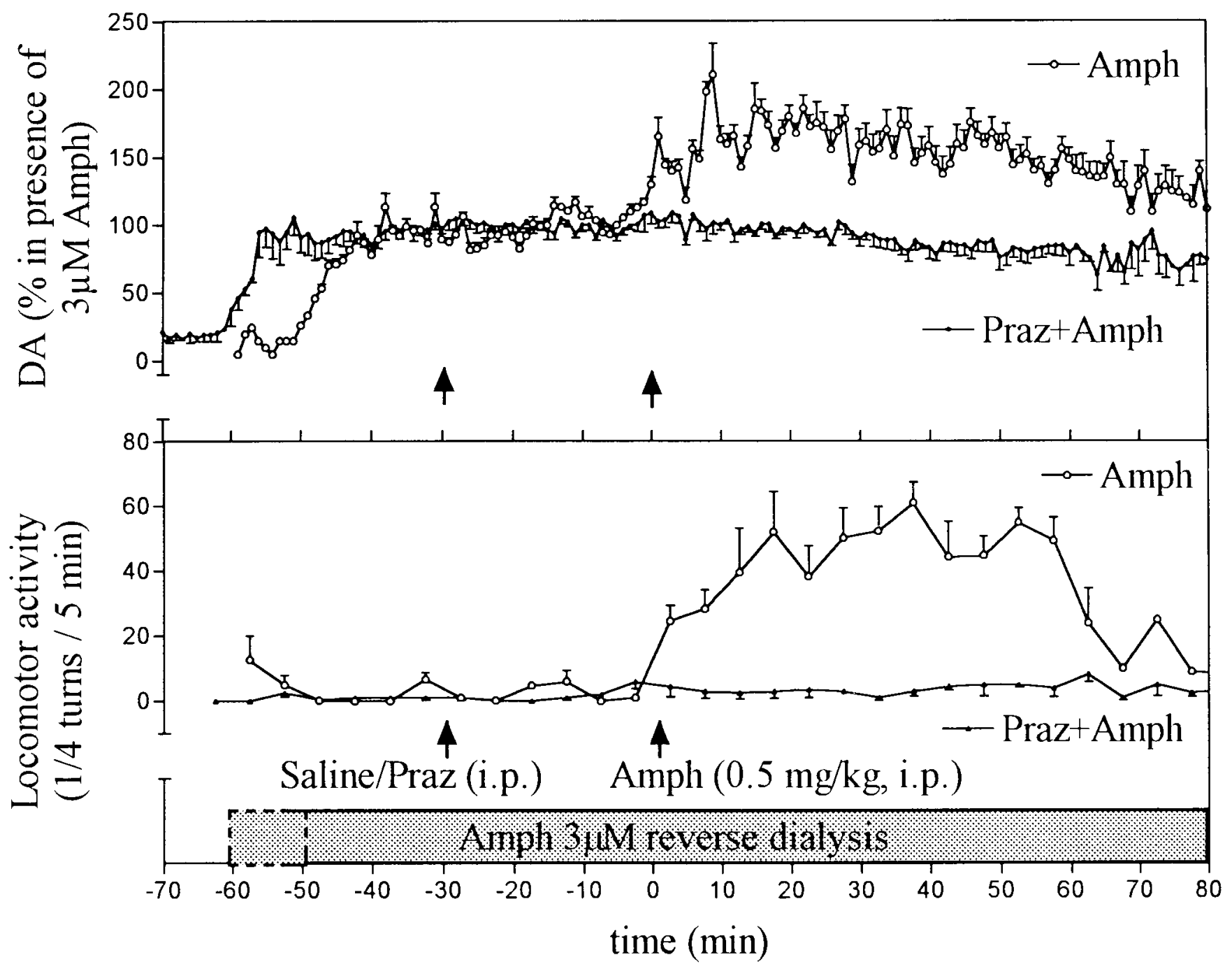

Figure 3. Blockade by prazosin $(0.5 \mathrm{mg} / \mathrm{kg}$, i.p. $)$ of the changes in extracellular DA levels in the nucleus accumbens and in locomotor response to a systemic injection of D-amphetamine $(0.5 \mathrm{mg} / \mathrm{kg}$, i.p.) in animals continuously perfused with D-amphetamine $(3 \mu \mathrm{M})$ in the nucleus accumbens. Animals were continuously perfused locally in the nucleus accumbens with $3 \mu \mathrm{M} \mathrm{D}$-amphetamine. Thirty minutes after injection of prazosin $(0.5 \mathrm{mg} / \mathrm{kg}$, i.p.; $n=$ $5)$ or saline $(n=6)$, D-amphetamine was injected intraperitoneally $(0.5 \mathrm{mg} / \mathrm{kg})$. Extracellular DA levels are expressed as the mean \pm SEM in percent of baseline defined as the mean value of 30 consecutive samples collected immediately before D-amphetamine intraperitoneal injection. Arrows indicate the time of prazosin-saline and D-amphetamine injections. DA levels in fractions 6-60 for saline- plus amphetamine-injected animals are significantly different from baseline $(+64 \% ; p<0.0001)$ and significantly different from those estimated in fractions $6-60$ for prazosin- plus amphetamine-injected animals $(+70 \% ; p<0.0001$; see Results). Behavioral data are given in absolute values (mean $\pm \mathrm{SEM})$.

\section{Suppression by bilateral injections of prazosin into the prefrontal cortex of the enhanced extracellular DA levels in the nucleus accumbens and locomotor activity evoked by the systemic injection of a low dose of D-amphetamine}

As shown previously, prazosin injected into the prefrontal cortex inhibits the locomotor hyperactivity induced by D-amphetamine infusion into the nucleus accumbens (Blanc et al., 1994). This observation led us to test the effects of cortical in situ inf usion of prazosin on systemic D-amphetamine-induced increases in DA levels and locomotor activity. On the first day of the experiment, animals were injected with saline in the prefrontal cortex and, 30 min later, with systemic D-amphetamine $(0.5 \mathrm{mg} / \mathrm{kg}$, i.p. $)$. The following day, 500 pmol of prazosin was injected bilaterally into the prefrontal cortex 30 min before systemic D-amphetamine injection. As shown in Figure 7, in these conditions, prazosin prevented the increases in extracellular DA levels and in locomo- tor activity induced by the systemic injection of D-amphetamine as well as the increases observed when prazosin was injected systemically (Fig. 3). However, likely caused by the presence of the cannula guides in the prefrontal cortex, the mean increase of extracellular DA levels induced in the nucleus accumbens by the systemic injection of D-amphetamine was of smaller amplitude $(+37 \% ; p<0.001 ; n=3)$. Extracellular DA levels of salinepretreated animals were significantly higher than those of the four animals having received prazosin $\left(+42 \% ; F_{(1,272)}=1241 ; p<\right.$ 0.0001).

\section{DISCUSSION}

The first main finding of these experiments is that absolute extracellular DA levels in the nucleus accumbens are not the sole factor responsible for the development of locomotor hyperactivity. Such a possibility has already been proposed by others when they analyzed the relationship between amphetamine-induced 


\section{Saline}
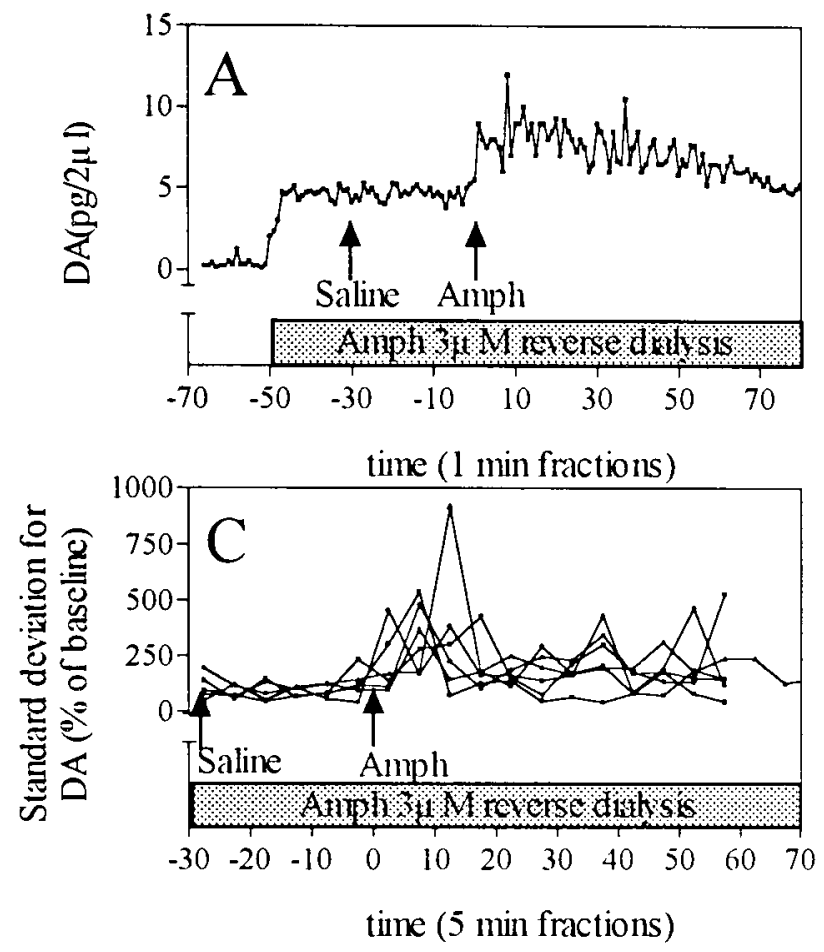

\section{Prazosin}
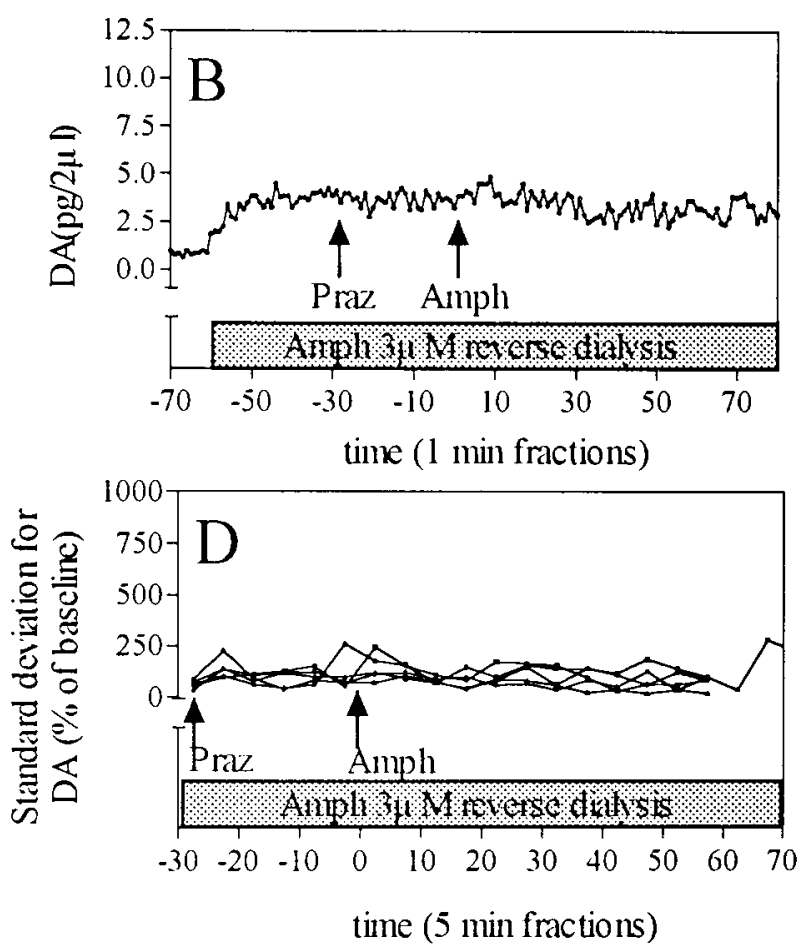

\section{Saline vs Prazosin}

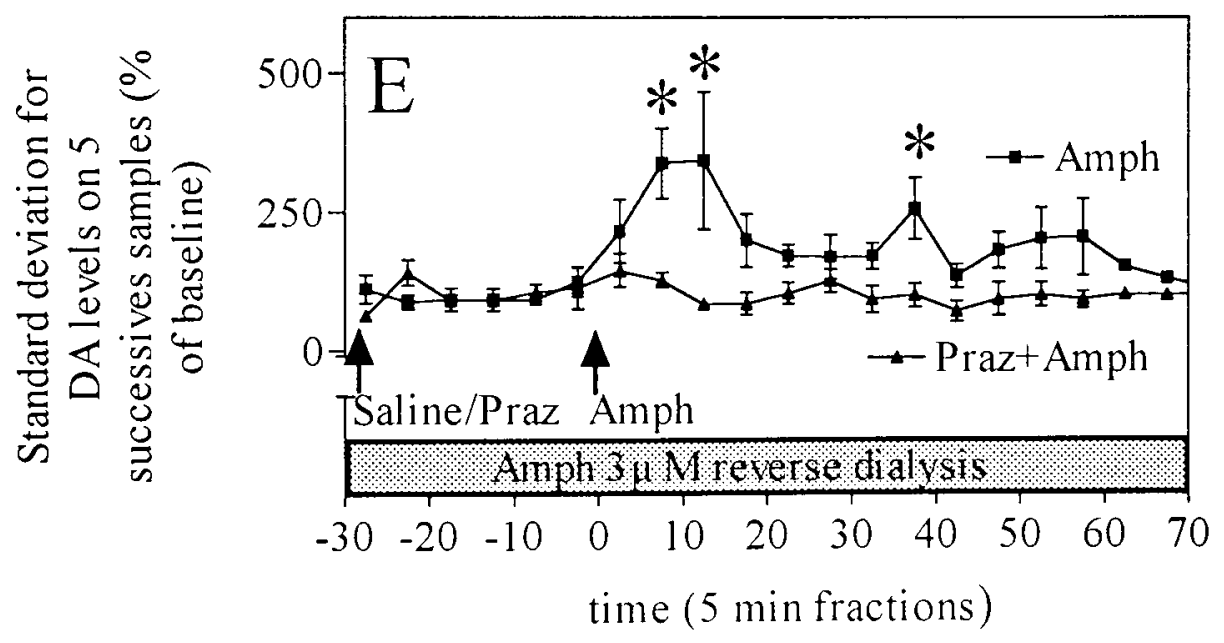

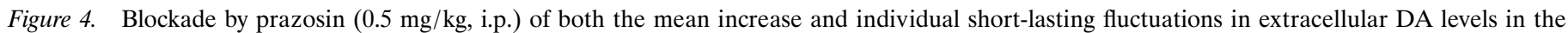

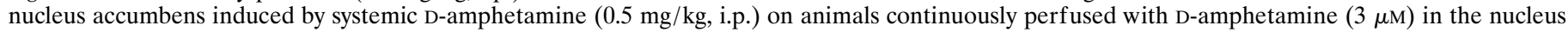

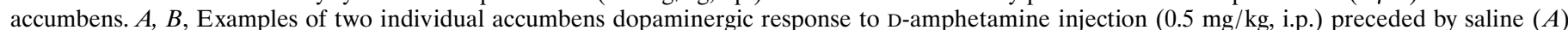

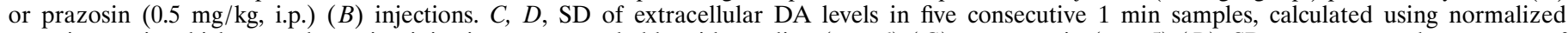

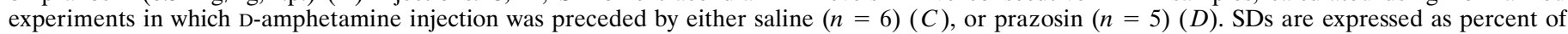

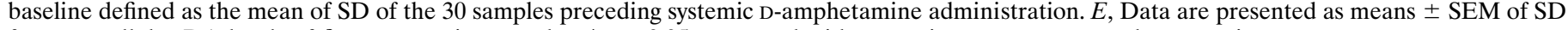
for extracellular DA levels of five consecutive samples. ${ }^{*} p<0.05$ compared with prazosin pretreatment at the same time.

DA response and behavioral sensitization to amphetamine (Segal and Kuczenski, 1992). Other authors have also observed a discrepancy between biochemical and behavioral events, especially when monoamine oxidase inhibitors were applied (Pani et al., 1990; Blaha et al., 1996). In our case, prazosin, which inhibits the D-amphetamine-induced locomotor hyperactivity, does not mod- ify the extracellular DA response in the nucleus accumbens after the intraperitoneal administration of $2 \mathrm{mg} / \mathrm{kg}$ D-amphetamine (Fig. 1). Moreover, the locomotor hyperactivity induced by the systemic injection of a low dose of D-amphetamine is associated with relatively modest increases of extracellular DA levels in the nucleus accumbens when they are compared with dramatic do- 


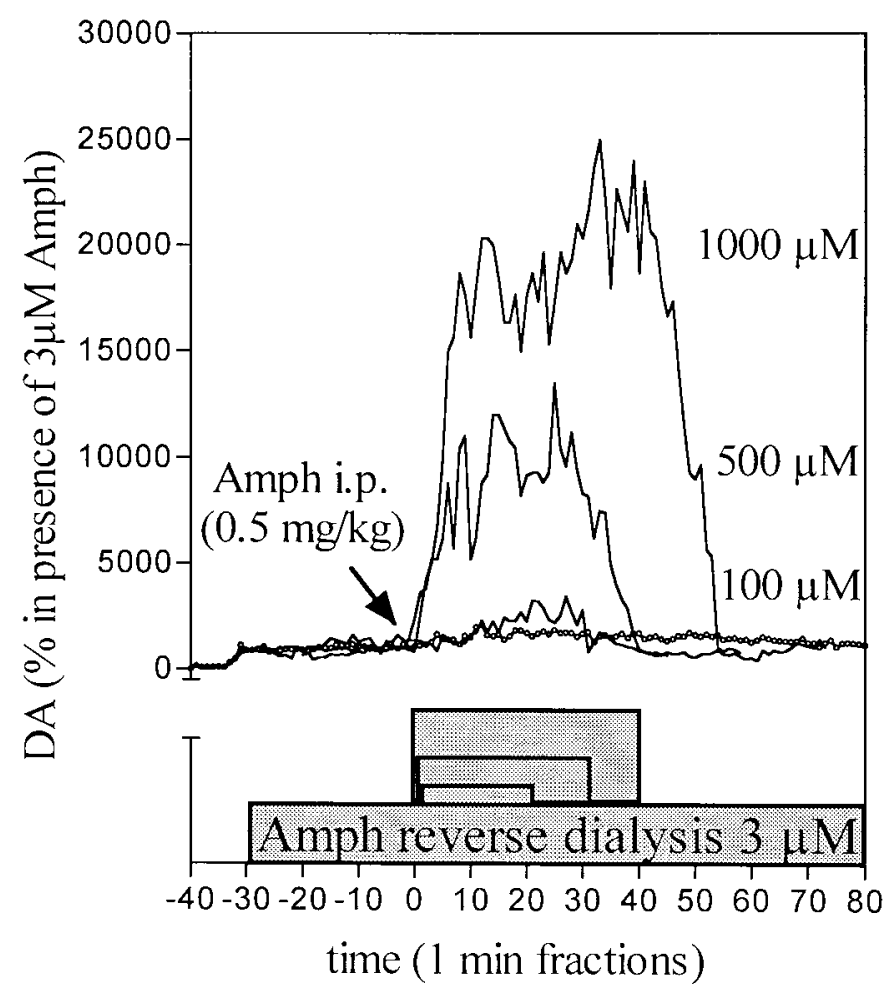

Figure 5. Local increases in extracellular DA levels induced by reverse dialysis perfusion of different concentrations of D-amphetamine in the nucleus accumbens. First, $3 \mu \mathrm{M}$ D-amphetamine was continuously applied, and $30 \mathrm{~min}$ after the beginning of this application, different concentrations of D-amphetamine (100, 500, and $1000 \mu \mathrm{M})$ were perfused for 20, 30, and $40 \mathrm{~min}$, respectively. Data are expressed as percent of baseline defined as the mean value of DA recovered in 30 consecutive samples collected immediately before 100,000 or $1000 \mu \mathrm{M}$ D-amphetamine perfusion. For comparison, data from Figure 3 have been plotted. They show the amplitude of the increase in extracellular DA levels induced by an intraperitoneal injection of D-amphetamine $(0.5 \mathrm{~m} / \mathrm{kg})$ in animals previously perfused locally in the nucleus accumbens with $3 \mu \mathrm{M}$ $\mathrm{D}$-amphetamine. As shown previously, data are expressed as percent of baseline defined as the mean value of 30 consecutive samples collected immediately before D-amphetamine intraperitoneal injection. Only animals perfused bilaterally in the nucleus accumbens with $1000 \mu \mathrm{M}$ D-amphetamine and those having received the intraperitoneal injection of D-amphetamine exhibited locomotor hyperactivity.

paminergic responses caused by bilateral local perfusions of 500 $\mu \mathrm{M}$ D-amphetamine (Fig. 5) that do not induce any behavioral activation. Previous studies have shown that significant locomotor hyperactivity could only be obtained when at least $4.0 \mathrm{nmol}$ of D-amphetamine was injected into each nucleus accumbens (Vezina et al., 1991). If we assume, as shown by Pan et al. (1996), that $\sim 10 \%$ of $\mathrm{D}$-amphetamine perfused in the microdialysis probe can diffuse through the membrane, a 30 min perfusion of $500 \mu \mathrm{M}$ D-amphetamine at a rate of $2 \mu \mathrm{l} / \mathrm{min}$ may correspond to a local injection of $3 \mathrm{nmol}$ of D-amphetamine. In agreement with our findings, the perfusion of a concentration of $>500 \mu \mathrm{M}$ D-amphetamine, and therefore a local increase in extracellular DA levels of $>12,500 \%$ of the basal values, would thus be necessary to elicit locomotor hyperactivity. Complementary experiments, using two distant probes located in the same nucleus accumbens, have shown that a perfusion of $500 \mu \mathrm{M}$ D-amphetamine induces a $2500 \%$ mean increase in extracellular DA levels in the entire structure, including the core and the shell (Zahm and Brog, 1992; Pierce and Kalivas, 1995), and that this is
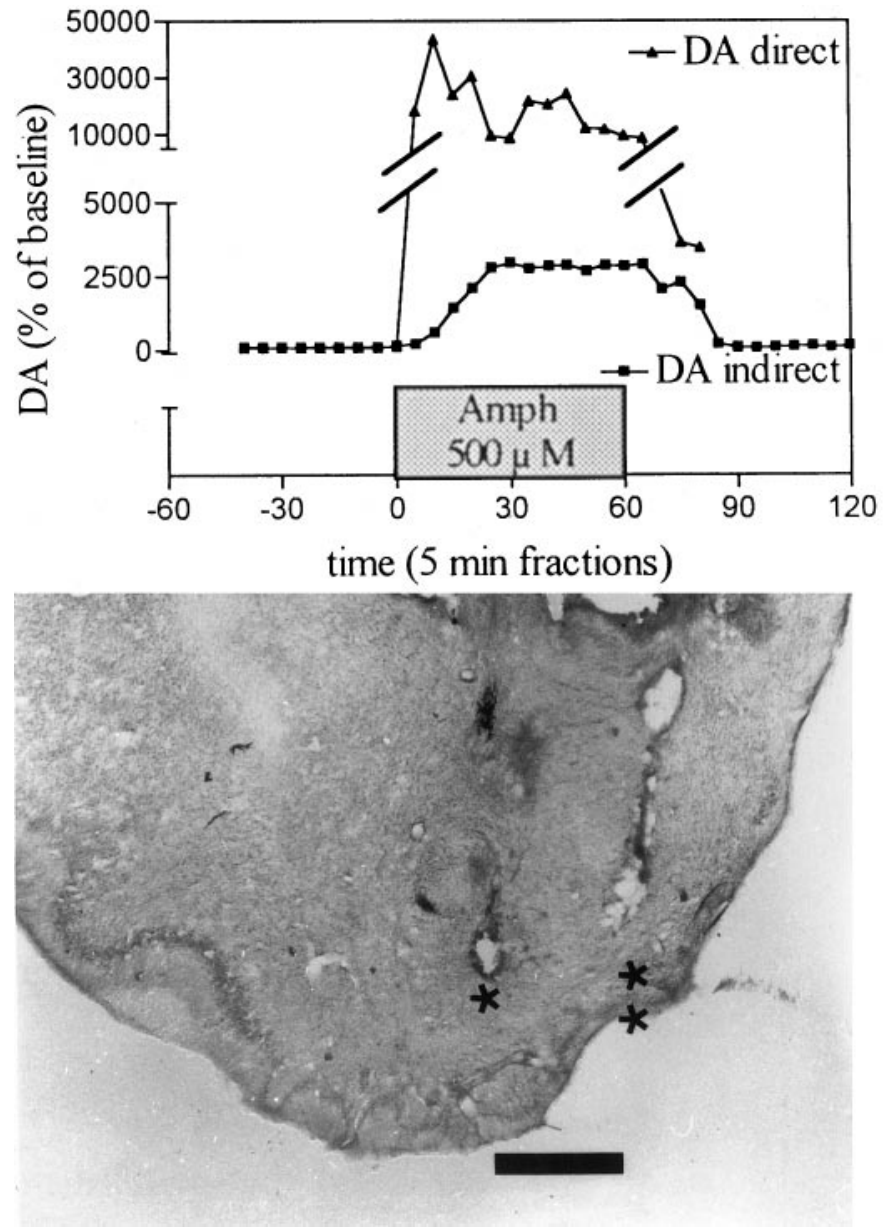

Figure 6. Analysis of the diffusion of the perfused D-amphetamine throughout the nucleus accumbens. D-Amphetamine $(500 \mu \mathrm{M})$ was perfused in the probe central to the nucleus accumbens $(*)$, and DA was measured in samples collected every $5 \mathrm{~min}$ from the central probe $(D A$ direct) and from a second probe $\left({ }^{* *}\right)$ placed $1 \mathrm{~mm}$ apart $(D A$ indirect $)$. Data are expressed as percent of baseline defined as the mean value of five consecutive samples collected immediately before any D-amphetamine local application. Scale bar, $1 \mathrm{~mm}$.

not sufficient to induce behavioral activation (Fig. 6). The requirement of much larger DA levels increasing to get a functional response when D-amphetamine is injected locally instead of systemically is confirmed by noting that when authors have trained rats to self-administer $\mathrm{D}$-amphetamine bilaterally in the nucleus accumbens, each depression of the drug lever was set to deliver 3 nmol of D-amphetamine in each structure (Phillips et al., 1994).

The second main finding of our experiments is that, on animals previously perfused locally with $3 \mu \mathrm{M}$ D-amphetamine, the blockade of $\alpha 1$-adrenergic receptors by prazosin hampers both the superimposed increases in extracellular DA levels in the nucleus accumbens and the locomotor hyperactivity induced by a low dose of systemic D-amphetamine. These effects are observed when prazosin is injected either systemically or locally into both prefrontal cortices. Prazosin is an antagonist of $\alpha 1$-adrenergic receptors recommended as a reference compound by the International Union of Pharmacology (Bylund et al., 1994). Prazosin can also bind to $\alpha 2 \mathrm{~B}$ - and $\alpha 2 \mathrm{C}$-adrenergic receptors but with an affinity at least 100 -fold lower than to $\alpha 1 \mathrm{~A}-, \alpha 1 \mathrm{~B}$, or $\alpha 1 \mathrm{D}-$ adrenergic receptors (Bylund et al., 1994). Moreover, because the 


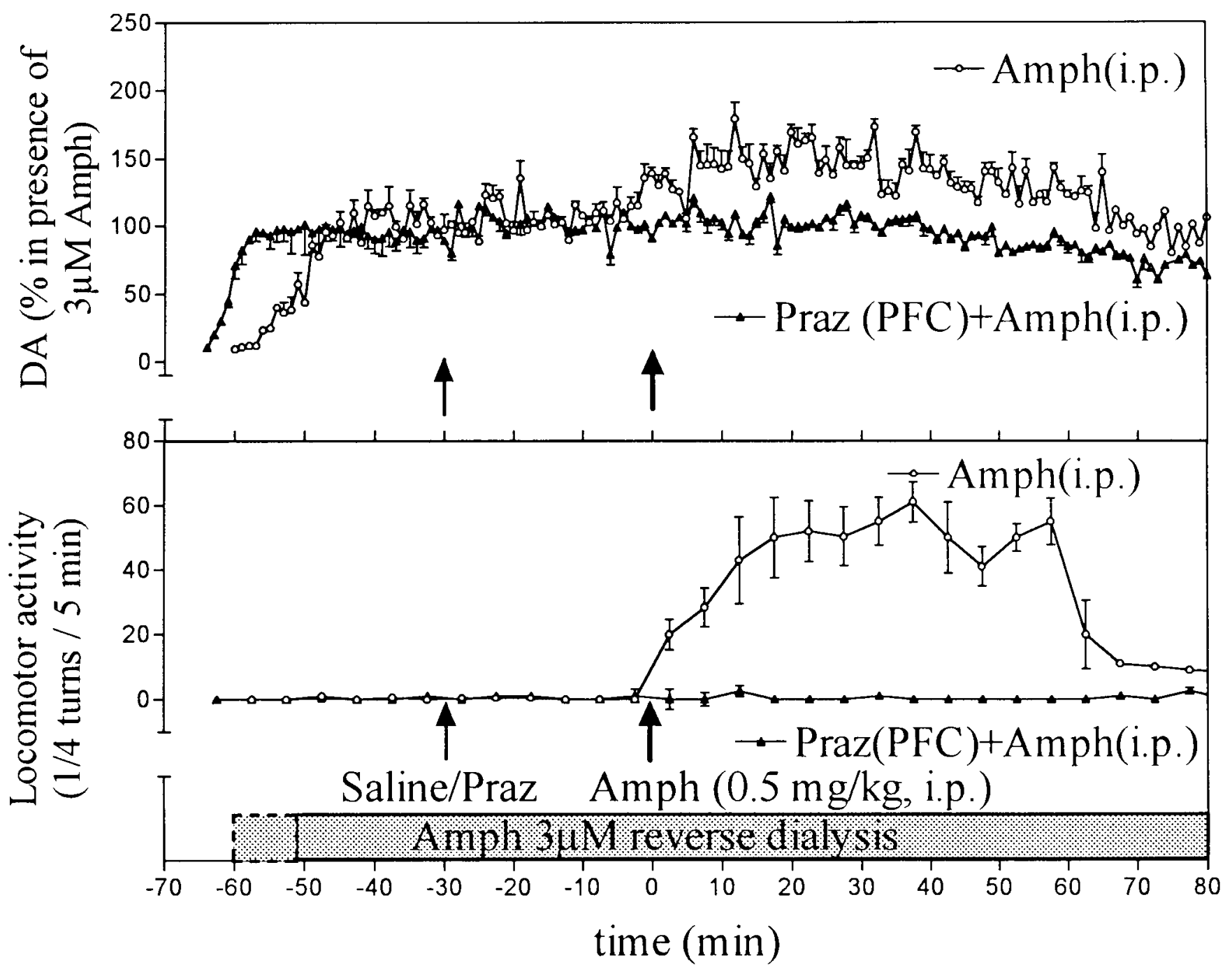

Figure 7. Blockade by bilateral injection of prazosin into the prefrontal cortex of the changes in the extracellular DA levels of the nucleus accumbens and locomotor activity induced by the peripheral injection of D-amphetamine ( $0.5 \mathrm{mg} / \mathrm{kg}$, i.p.). Animals were continuously perfused locally in the nucleus accumbens with $3 \mu \mathrm{M}$ D-amphetamine and received bilateral local injection of either prazosin $(500 \mathrm{pmol} / \mathrm{side} ; n=4)$ or saline $(n=3)$ in the prefrontal cortex. D-Amphetamine was injected intraperitoneally $(0.5 \mathrm{mg} / \mathrm{kg}) 30 \mathrm{~min}$ after the cortical injection. Data corresponding to the mean \pm SEM are expressed as percent of baseline defined as the mean value of DA recovered in 30 consecutive samples collected immediately before D-amphetamine intraperitoneal injection. DA levels from fractions 6-60 for saline- plus amphetamine-injected animals were significantly different from baseline $(+37 \%$; $p<0.0001)$ and significantly different from DA levels of fractions $6-60$ for prazosin- plus amphetamine-injected animals $(+42 \% ; p<0.0001 ;$ see Results). Behavioral data are given in absolute values (mean \pm SEM). PFC, Prefrontocortical injection.

prefrontocortical injection of 2-(2',6'-dimethoxyphenoxyethyl) aminomethyl-1,4-benzodioxane, another $\alpha 1$-adrenergic antagonist with no affinity for $\alpha 2$-adrenergic receptors, exhibits the same blocking effect as prazosin on the locomotor hyperactivity induced by the local injection of D-amphetamine into the nucleus accumbens (Blanc et al., 1994), there is little doubt that the effects of prazosin on D-amphetamine-induced increases of extracellular DA levels are attributable to the blockade of $\alpha 1$-adrenergic receptors.

\section{Local (nucleus accumbens) and distal effects of D-amphetamine}

After the superfusion of D-amphetamine in the nucleus accumbens, the increase of extracellular DA levels induced by the systemic injection of D-amphetamine could be also attributed to a local (nucleus accumbens) effect of the superimposed injection of $\mathrm{D}$-amphetamine. This is probably not the case, because systemic prazosin, which, as we have shown, does not modify local effects of D-amphetamine on DA levels (Fig. 2), is able to block the increases of DA levels induced by the superimposed systemic D-amphetamine. It is therefore very likely that the increases of extracellular DA levels induced by systemic D-amphetamine after its superfusion in the nucleus accumbens are attributable to effects of D-amphetamine distal to the nucleus accumbens. It cannot be excluded, however, that, by blocking the DA reuptake process, the local superfusion of D-amphetamine makes the distal effects of systemic D-amphetamine on nucleus accumbens DA levels more readily detectable. This may explain why no effect of prazosin can be observed on DA levels when D-amphetamine is injected systemically without its combined previous local perfusion (Fig. 1). Altogether, our experiments suggest that the nucleus accumbens DA release induced by a systemic injection of $\mathrm{D}$-amphetamine is modulated by a D-amphetamine-induced in- 
crease of NA transmission occurring distally from the nucleus accumbens.

\section{Noradrenergic effects of D-amphetamine in the VTA}

As already indicated, in some conditions, the peripheral injection of D-amphetamine in high doses inhibits the firing rate of dopaminergic cells in the VTA (Wang, 1981). Nevertheless, different experiments suggest that $\mathrm{D}$-amphetamine can increase the activity of dopaminergic neurons through the stimulation of $\alpha 1$ adrenergic receptors in the VTA. For example, Pan et al. (1996) have shown that the perfusion of high doses of D-amphetamine in the VTA of anesthetized animals increases extracellular DA levels in the nucleus accumbens and the medial prefrontal cortex, these effects being blocked by coinf usion with D-amphetamine of phentolamine, an $\alpha 1$-adrenergic antagonist. This excitatory action of VTA NA transmission on dopaminergic neurons seems, however, more specific to mesocortical than to mesolimbic dopaminergic neurons, because phentolamine was 10 -fold more active on prefrontocortical than on nucleus accumbens DAincreased release (Pan et al., 1996). Similarly, when a specific noradrenergic denervation of the VTA was performed, it was found that only the DA utilization in the prefrontal cortex was decreased, whereas no change occurred in the nucleus accumbens (Hervé et al., 1982).

Intracellular recordings in VTA slices have shown that local adrenergic mechanisms can either excite or inhibit dopaminergic cells (Grenhoff et al., 1995). Previous electrophysiological studies indicated that the peripheral injection of prazosin dosedependently decreases burst firing and regularizes the firing pattern of VTA dopaminergic neurons, but the firing rate is not affected (Grenhoff and Svensson, 1993).

All of these experiments, especially the latter, do not exclude that the NA transmission of the prefrontal cortex plays a major role in the modulation of DA release in the nucleus accumbens, a possibility strongly suggested by our data on the effects of prazosin injected locally in the prefrontal cortex on D-amphetamine-induced DA release in the nucleus accumbens (Fig. 7).

\section{Noradrenergic effects of D-amphetamine in the prefrontal cortex}

Microdialysis studies performed in behaving animals have indicated that the systemic injection of a small dose of D-amphetamine induces an important increase in the extracellular NA levels of the prefrontal cortex (Florin et al., 1994). Local injections of prazosin in the prefrontal cortex may therefore block the effects of this increased cortical NA release on $\alpha 1$-adrenergic receptors. We have previously shown that the blockade of cortical $\alpha 1$-adrenergic receptors facilitates the DA transmission mediated through D1 receptors in the prefrontal cortex (Vezina et al., 1991; Blanc et al., 1994; Tassin et al., 1995). The inhibitory properties of prazosin on D-amphetamine-induced increases in extracellular DA levels of the nucleus accumbens and in locomotor activity may therefore be attributable to an inhibition of the activity of glutamatergic excitatory cortical neurons, bearing D1 receptors and projecting directly or indirectly through the nucleus accumbens, to the VTA (Thierry et al., 1979; Sesack and Pickel, 1992; Karreman and Moghaddam, 1996). Increased releases of DA in the nucleus accumbens could be attributable to an effect of glutamate on presynaptic receptors located on dopaminergic nerve terminals, as shown for the caudate nucleus (Chéramy et al., 1986), but also, more probably, to a direct effect of glutama- tergic cells on the VTA, because the stimulation of prefrontocortical neurons selectively increases burst firing in the VTA and enhances the release of DA in the nucleus accumbens (Murase et al., 1993). Moreover, the stimulation of D1 receptors in the VTA increases the release of glutamate in this structure (Kalivas and Duffy, 1995), and the intra-VTA injection of Schering-Plough $\mathrm{R}(+)$-2,3,4,5-tetrahydro-3-methyl-5-phenyl-1H-3 benzazepin-7ol, an antagonist of D1 receptors, blocks the locomotor hyperactivity induced by systemic D-amphetamine (Vezina, 1996). Altogether, the stimulation of cortical $\alpha 1$-adrenergic receptors by systemic D-amphetamine may facilitate DA transmission in the nucleus accumbens through a cortico-VTA glutamatergic pathway that would drive VTA dopaminergic cells into a bursting activity.

\section{Are D-amphetamine effects on DA release totally independent of impulse flow?}

Systemic D-amphetamine injections were shown to increase the DA release in the nucleus accumbens induced by electrical stimulations of the ascending DA pathway (Dugast et al., 1994), strongly suggesting that $\mathrm{D}$-amphetamine amplifies DA responses when dopaminergic neurons are activated. Our proposition that systemic D-amphetamine indirectly drives VTA dopaminergic neurons into a bursting activity that induces increased DA release in the nucleus accumbens implies that at least part of the D-amphetamine-induced increases of extracellular DA levels in the nucleus accumbens is dependent on the impulse flow. This part may, however, be relatively small and difficult to detect by conventional methods. Experiments by Von Voigtlander and Moore (1973) concluded that D-amphetamine-induced DA release was dependent on impulse flow, but more recent studies (Westerink et al., 1987; Kuczenski et al., 1990) reached the opposite conclusion. Nevertheless, in their experiments with TTX, Westerink et al. (1987) noted that the absolute amphetamine-induced increase of DA during TTX infusion is $35 \%$ less than without TTX infusion, suggesting that a contribution of impulse flow to amphetamine-enhanced synaptic DA cannot be ruled out. Finally, it seems difficult to reconcile the fact that the D-amphetamine-induced NA release is clearly impulse flow-dependent at low doses (Florin et al., 1994) with the notion that D-amphetamine-induced DA release is absolutely not.

After the perfusion of D-amphetamine, the systemic injection of D-amphetamine induces not only a mean increase of extracellular DA levels in the nucleus accumbens, but also important fluctuations of DA levels (Fig. 4). These fluctuations of DA levels cannot be attributed to a lack of reliability of the 1 min sample collection because such variations disappear in presence of prazosin (Fig. 4). These fluctuations may be attributable to shortlasting (in few seconds range) bursting activities of VTA dopaminergic neurons triggering abrupt increases of DA release (Chergui et al., 1994). This hypothesis is not incompatible with the microdialysis technique, because we have observed that the immersion of a dialysis probe in a $3 \mu \mathrm{M}$ DA solution for $1 \mathrm{sec}$ was enough to detect a signal with our HPLC electrochemical apparatus (Gillibert, 1994), and similar data have been reported by others (Bert et al., 1996).

\section{Functional and not functional DA release?}

Our data indicate that $\mathrm{D}$-amphetamine focal application requires at least a 4.8-fold higher increase in DA output in the entire nucleus accumbens compared with systemic D-amphetamine for the behavioral effects to be elicited. This would mean that only 
$\leq 20 \%$ of the DA released in the nucleus accumbens is functional after the focal application of D-amphetamine, this part being blocked by the local application of prazosin in the prefrontal cortex. To characterize this functional DA, two nonexclusive hypotheses could be proposed. First, it is possible that only the part of DA that is released in co-occurrence with the glutamic acid arising from cortical afferent fibers has a behavioral consequence. A second hypothesis could be that, to be functional, DA has to be released as short bursts occurring simultaneously in the entire target structure. One way to achieve this simultaneous release of DA would be an electrotonic coupling of VTA dopaminergic neurons. Such a possibility of synchronization of the firing pattern of dopaminergic neurons has already been documented by Grace and Bunney (1983), who have obtained electrophysiological and morphological evidence for an electrotonic coupling of dopaminergic cells in the SN. Experiments are in progress to test both hypotheses.

\section{Conclusions}

This study has confirmed that D-amphetamine exerts its psychostimulant properties through an activation of both NA and DA systems. Only a small part $(\leq 20 \%)$ of the D-amphetamineinduced DA release is associated with the behavioral activation observed after a systemic D-amphetamine injection. This functional part of the released DA would be under the control of the NA stimulation of prefrontocortical $\alpha 1$-adrenergic receptors. The facilitation of cortical NA transmission induced by systemic D-amphetamine would either modify glutamic acid release in the nucleus accumbens or indirectly drive VTA dopaminergic neurons into short-lasting, eventually synchronized, bursts triggering increased release of DA in the entire nucleus accumbens. It is very likely that other psychostimulants, such as cocaine, which inhibits reuptake of catecholamines in noradrenergic neurons as well as in dopaminergic cells, exert their psychotropic effects via a similar coupling between noradrenergic and dopaminergic cells. This synergy between noradrenergic and dopaminergic cells is probably weaker or absent after treatments with some other abused drugs, such as opioids, which activate dopaminergic neurons but inhibit noradrenergic transmission (Korf et al., 1974). This may explain why, in humans, the behavioral consequences of ingestion of psychostimulants are clearly different from what is observed with morphine or heroin.

\section{REFERENCES}

Akaoka H, Roussel B, Lin JS, Chouvet G, Jouvet M (1991) Effect of modafinil and amphetamine on the rat catecholaminergic neuron activity. Neurosci Lett 123:20-22.

Andersen PH (1989) The dopamine uptake inhibitor GBR 12909: selectivity and molecular mechanism of action. Eur $\mathrm{J}$ Pharmacol 166:499-504.

Angrist BM, Shopsin B, Gershon S (1971) Comparative psychomimetic effects of stereoisomers of amphetamine. Nature 234:152-153.

Angrist BM, Sathananthan G, Wilk S, Gershon S (1974) Amphetamine psychosis: behavioral and biochemical aspects. J Psychiatr Res 11:13-23.

Bert L, Robert L, Denoroy L, Stoppini L, Renaud B (1996) Enhanced temporal resolution for the microdialysis monitoring of catecholamines and excitatory amino acids using capillary electrophoresis with laserinduced fluorescence detection. Analytical developments and in vitro validations. J Chromatogr A 755:99-111.

Besson M, Cheramy A, Feltz P, Glowinski J (1971) Dopamine: spontaneous and drug-induced release from the caudate nucleus in the cat. Brain Res 32:407-424.

Blaha CD, Coury A, Phillips AG (1996) Does monoamine oxidase inhibition by pargyline increase extracellular dopamine concentrations in the striatum? Neuroscience 75:543-550.
Blanc G, Trovero F, Vezina P, Hervé D, Godeheu A-M, Glowinski J, Tassin J-P (1994) Blockade of prefronto-cortical $\alpha 1$-adrenergic receptors prevents locomotor hyperactivity induced by subcortical D-amphetamine injection. Eur J Neurosci 6:293-298.

Bunney BS, Aghajanian GK (1976) d-Amphetamine-induced inhibition of central dopaminergic neurons: mediation by a striato-nigral feedback pathway. Science 192:391-393.

Bunney BS, Aghajanian GK (1978) d-Amphetamine-induced depression of central dopamine neurons: evidence for mediation by both autoreceptors and striato-nigral feedback pathway. Naunyn Schmiedebergs Arch Pharmacol 304:255-261.

Bunney BS, Walters JR, Kuhar MJ, Roth RH, Aghajanian GK (1975) D\& L-Amphetamine stereoisomers: comparative potencies in affecting the firing of central dopaminergic and noradrenergic neurons. Psychopharmacol Commun 1:177-190.

Bylund DB, Eikenberg C, Hieble JP, Langer SZ, Lefkowitz RJ, Minneman KP, Molinoff PB, Ruffolo Jr RR, Trendelenburg U (1994) IV International Union of Pharmacology: nomenclature of adrenoreceptors. Pharmacol Rev 46:121-128.

Cadoni C, Pinna A, Russi G, Consolo S, Di Chiara G (1995) Role of vesicular dopamine in the in vivo stimulation of striatal dopamine transmission by amphetamine: evidence from microdialysis and fos immunohistochemistry. Neuroscience 65:1027-1039.

Chéramy A, Romo R, Godeheu G, Baruch P, Glowinski J (1986) In vivo presynaptic control of dopamine release in the cat caudate nucleus. II. Facilitatory or inhibitory influence of L-glutamate. Neuroscience 19:1081-1090.

Chergui K, Suaud-Chagny MF, Gonon F (1994) Nonlinear relationship between impulse flow, dopamine release and dopamine elimination in the rat brain in vivo. Neuroscience 62:641-645.

Dickinson SL, Gadie B, Tulloch F (1988) $\alpha 1$ - and $\alpha 2$-Adrenoreceptor antagonists differentially influence locomotor and stereotyped behaviour induced by D-amphetamine and apomorphine in the rat. Psychopharmacology 96:521-527.

Dugast C, Suaud-Chagny MF, Gonon F (1994) Continuous in vivo monitoring of evoked dopamine release in the rat nucleus accumbens by amperometry. Neuroscience 62:647-654.

Florin SM, Kuczenski R, Segal DS (1994) Regional extracellular norepinephrine responses to amphetamine and cocaine and effects of clonidine pretreatment. Brain Res 654:53-62.

Gillibert C (1994) Release of monoamines in the prefrontal cortex of the rat during the sleep-wake cycle: a microdialysis study. DEA thesis, University of Paris VI, Paris, France.

Grace AA, Bunney BS (1983) Intracellular and extracellular electrophysiology of nigral dopamine neurons. 3. Evidence for electrotonic coupling. Neuroscience 10:333-348.

Grenhoff J, Svensson TH (1993) Prazosin modulates the firing pattern of dopamine neurons in rat ventral tegmental area. Eur J Pharmacol 233:79-84.

Grenhoff J, North RA, Johnson SW (1995) Alpha 1-adrenergic effects on dopamine neurons recorded intracellularly in the rat midbrain slice. Eur J Neurosci 7:1707-1713.

Heikkila RE, Orlansky H, Mytilineou C, Cohen G (1975) Amphetamine: evaluation of $\mathrm{D}$ - and L-isomers as releasing agents and uptake inhibitors for ${ }^{3} \mathrm{H}$-dopamine and ${ }^{3} \mathrm{H}$-norepinephrine in slices of rat neostriatum and cerebral cortex. J Pharmacol Exp Ther 194:47-56.

Hervé D, Blanc G, Glowinski J, Tassin JP (1982) Reduction of dopamine utilization in the prefrontal cortex but not in the nucleus accumbens after selective destruction of noradrenergic fibers innervating the ventral tegmental area in the rat. Brain Res 237:510-516.

Janowski D, Davis JM (1976) Methylphenidate dextroamphetamine and levoamphetamine. Arch Gen Psychiatry 33:304-308.

Kalivas PW, Duffy P (1995) D1 receptors modulate glutamate transmission in the ventral tegmental area. J Neurosci 15:5379-5388.

Karreman M, Moghaddam B (1996) The prefrontal cortex regulates the basal release of dopamine in the limbic striatum: an effect mediated by ventral tegmental area. J Neurochem 66:589-598.

Kelly PH, Seviour PW, Iversen SD (1975) Amphetamine and apomorphine responses in the rat following 6-hydroxydopamine lesions of the nucleus accumbens septi and corpus striatum. Brain Res 94:507-522.

Kokkinidis L, Anisman H (1978) Involvement of norepinephrine in startle arousal after acute and chronic D-amphetamine administration. Psychopharmacology 59:285-292.

Kokkinidis L, Anisman H (1979) Circling behaviour following systemic 
D-amphetamine administration: potential noradrenergic and dopaminergic involvement. Psychopharmacology 64:45-54.

Korf J, Bunney BS, Aghajanian GK (1974) Noradrenergic neurons: morphine inhibition of spontaneous activity. Eur J Pharmacol 25:165-169.

Kuczenski R, Segal DS (1992) Differential effects of amphetamine and dopamine uptake blockers (cocaine, nomifensine) on caudate and accumbens dialysate dopamine and 3-methoxytyramine. J Pharmacol Exp Ther 262:1085-1094.

Kuczenski R, Segal DS, Manley LD (1990) Apomorphine does not alter amphetamine-induced dopamine release measured in striatal dialysates. J Neurochem 54:1492-1498.

Lyon M, Robbins TW (1975) The action of central nervous system drugs: a general theory concerning amphetamine effects. In: Current developments in psychopharmacology, Vol 2 (Essman W, Valzelli L, eds), pp 79-163. New York: Spectrum.

Murase S, Grenhoff J, Chouvet G, Gonon FG, Svensson TH (1993) Prefrontal cortex regulates burst firing and transmitter release in rat mesolimbic dopamine neurons studied in vivo. Neurosci Lett 157:53-56.

Pan WH, Sung JC, Fuh SM (1996) Locally application of amphetamine into the ventral tegmental area enhances dopamine release in the nucleus accumbens and the medial prefrontal cortex through noradrenergic neurotransmission. J Pharmacol Exp Ther 278:725-731.

Pani L, Gessa GL, Carboni S, Portas CM, Rossetti ZL (1990) Brain dialysis and dopamine: does the extracellular concentration of dopamine reflect synaptic release? Eur J Pharmacol 180:85-90.

Phillips GD, Robbins TW, Everitt BJ (1994) Bilateral intra-accumbens self-administration of d-amphetamine: antagonism with intra-accumbens SCH-23390 and sulpiride. Psychopharmacology 114:477-485.

Pierce RC, Kalivas P (1995) Amphetamine produces sensitized increases in locomotion and extracellular dopamine preferentially in the nucleus accumbens shell of rats administered repeated cocaine. J Pharmacol Exp Ther 275:1019-1029.

Pijnenburg AJ, Honig WM, Van-Rossum JM (1975) Inhibition of D-amphetamine-induced locomotor activity by injection of haloperidol into the nucleus accumbens of the rat. Psychopharmacology 41:87-95.
Porrino LJ, Lucignani G, Dow-Edwards D, Sokoloff L (1984) Correlation of dose dependent effects of acute amphetamine administration on behavior and local cerebral metabolism in rats. Brain Res 307:311-320.

Segal DS, Kuczenski R (1992) In vivo microdialysis reveals a diminished amphetamine-induced DA response corresponding to behavioral sensitization produced by repeated amphetamine pretreatment. Brain Res 571:330-337.

Sesack SR, Pickel VM (1992) Prefrontal cortical efferents in the rat synapse on unlabeled neuronal targets of catecholamine terminals in the nucleus accumbens septi and on dopamine neurons in the ventral tegmental area. J Comp Neurol 320:145-160.

Tassin JP, Trovero F, Vezina P, Blanc G, Glowinski J, Hervé D (1995) Receptor heteroregulation: an indication of functional relationships between neuronal systems. Médecine/Sciences 6:829-836.

Thierry AM, Deniau JM, Feger J (1979) Effects of stimulation of the frontal cortex on identified output VMT cells in the rat. Neurosci Lett 15:102-107.

Vezina P (1996) D1 dopamine receptor activation is necessary for the induction of sensitization by amphetamine in the ventral tegmental area. J Neurosci 16:2411-2420.

Vezina P, Blanc G, Glowinski J, Tassin JP (1991) Opposed behavioural outputs of increased dopamine transmission in prefronto-cortical and subcortical areas: a role for the cortical D1 dopaminergic receptor. Eur J Neurosci 3:1001-1007.

Von Voigtlander PF, Moore KE (1973) Involvement of nigro-striatal neurons in the in vivo release of dopamine by amphetamine, amantadine and tyramine. J Pharmacol Exp Ther 184:542-552.

Wang RY (1981) Dopaminergic neurons in the rat ventral tegmental area. III. Effects of D- and L-amphetamine. Brain Res Rev 3:153-165.

Westerink BHC, Tuntler J, Damsma G, Rollema H, de Vries JB (1987) The use of tetrodotoxin for the characterization of drug-enhanced dopamine release in conscious rats studied by brain dialysis. Naunyn Schmiedebergs Arch Pharmacol 336:502-507.

Zahm DS, Brog JS (1992) On the significance of subterritories in the "accumbens" part of the rat ventral striatum. Neuroscience 50:751-767. 